\title{
Normoalbuminuric Diabetic Kidney Disease- Need for Renal Biopsy? An Autopsy Study on Western Indian Population
}

\author{
Sonal Paul*, Nitin.M. Gadgil and Anitha Padmanabhan \\ Department of Pathology, Lokmanya Tilak Medical college and General Hospital, Sion, Mumbai, India
}

\begin{abstract}
Introduction: Persistent albuminuria and glomerular filtration rate are considered as the gold standard for the diagnosis of Diabetic Nephropathy (DN).

Methods: In this autopsy study, we evaluated data from a cohort of 67 patients with Type 2 Diabetes Mellitus. We determined the histological prevalence of DN irrespective of the clinical manifestations of renal disease. Patients were stratified by proteinuria and estimated glomerular filtration rate(eGFR). The glomerular, interstitial and vascular lesions were scored as per the established histopathologic classification for DN.

Results: 55 of the 67 patients had clinical as well as histological lesions consistent with DN. 12 patients had histological lesions of DN at autopsy but no clinical evidence of proteinuria, including microalbuminuria in their lifetime.4 of these patients had maintained eGFR.There was no difference in the glomerular lesions in patients with normoalbuminuria regardless of the eGFR. However,50\% of the patients with low eGFR showed presence of interstitial fibrosis and tubular atrophy while no interstitial lesions were noted in patients with normoalbuminuria and maintained eGFR. Significant amount of arteriosclerosis was noted in the normoalbuminuric low eGFR patients. Haematuria was significantly associated with proteinuric lowGFR patients.

Conclusion: Histological evidence of DN may be seen even in the absence of clinical manifestations,suggesting that, in diabetic kidneys some amount of glomerular and tubulointerstitial damage has already occurred before the onset of proteinuria. Hence, there is a need for routine kidney biopsies in diabetic patients with normoalbuminuria. This will help in the timely diagnosis and appropriate management in the early stages of DN.
\end{abstract}

Keywords: Diabetic Kidney Disease, Normoalbuminuria, Renal Biopsy.

\section{Introduction}

India has the largest number of Diabetic patients in the world, around 40.9 million in the year 2007 and expected to reach 69.9 million by the year 2025.The prevalence of Diabetic Nephropathy (DN) was reported as $2.2 \%$ in urban Asian Indians in a study by Unnikrishnan et al. ${ }^{[1]}$

One of the leading causes of end stage renal disease is DN, which develops in approximately $10-30 \%$ of the patients with Type 2 Diabetes Mellitus (DM). ${ }^{[2]}$. In 1994, Tsalamandria et al were the first to describe Diabetic patients who did not have clinically significant proteinuria, yet had renal insufficiency (eGFR $<60 \mathrm{ml} / \mathrm{min} / 1.73 \mathrm{~m}^{2}$ ) and progressed to Diabetic Kidney Disease (DKD). This condition was described as normoalbuminuric diabetic kidney disease (NADKD) ${ }^{[3]}$ Since then, there have been many studies which have reported that, there is a proportion of Diabetic patients who have Diabetic kidney disease without apparent proteinuria. ${ }^{[2,4]}$

One of the major manifestations of DKD is NADKD, but its prevalence varies across studies. This may be due to the different methods for measuring proteinuria or previous treatments to alleviate proteinuria. Thomas et al ${ }^{[5]}$ have described that the prevalence of NADKD is much higher among Caucasian population (91\%), than among indigenous Australians (2\%) and Asian population (7\%).

In 2015, the American Diabetes Association, proposed the latest diagnostic criteria for DKD which includes urinary albumin excretion rate $>30 \mathrm{mg} / 24 \mathrm{hrs}$ or eGFR $<60 \mathrm{ml} /$ $\min / 1.73 \mathrm{~m}^{2[6]}$

We have conducted this autopsy study, to evaluate the histological lesions of Diabetic Nephropathy in patients with or without clinical manifestations of renal disease.

\section{Method}

All medical autopsies in a 5-year period from July 2014July 2019 ( 3 years retrospective-2 years prospective), were included in this observational analytical cross-sectional study.

Approval was obtained from the Medical Ethics Committee of our institute to conduct this study as per guidelines. Consent for autopsy was already taken from the first degree relative of the deceased by the clinicians in all cases. 
Autopsies were documented with an individual protocol, including the medical history, the main diagnosis, and the final cause of death. The primary inclusion criteria were adult patients with Type 2 diabetes mellitus. Cases with incomplete or inadequate history of diabetes mellitus in the medical records were excluded. Similarly, diabetic cases with primary renal diseases were also excluded on the basis of the clinical history, examination, radiological and laboratory investigations done at the time of admission of the patient. These cases were also evaluated histologically post-mortem for the confirmation of primary renal disease.

Clinical data: The clinical information was obtained through the medical autopsy records. The following data was obtained: gender, age at death, co morbidities, duration of diabetes, medication history, hypertension, cause of death and autopsy findings. Data indicating a stable representation of serum and urine levels during terminal hospitalisation were included. The following laboratory parameters were included: BUN, serum creatinine, urine microalbuminuria in 24-hour urine sample, estimated glomerular filtration rate (eGFR), proteinuria determined by dipstick test, systolic and diastolic blood pressure and serum haemoglobin. The eGFR was estimated by using the CKD-Epi formula for Indian population:

GFR $\left(\mathrm{ml} / \mathrm{min} / 1.73 \mathrm{~m}^{2}\right)=166 \times(\text { S.creat } / 0.7)^{-0.329} \times(0.993)^{\text {age }}$

Histopathological Features: Renal tissue was fixed in $10 \%$ buffered formalin and embedded in paraffin. Slices were cut at $1-$ and 3- $\mu \mathrm{m}$ and stained with haematoxylin and eosin. Special stains like Periodic Acid Schiff, Masson's Trichrome and Silver Methenamine stain were performed wherever required. Renal tissue sections containing 100 glomeruli or more were reviewed by two investigators. Sections from both the right as well as the left kidney were analysed. Glomerular lesions, interstitial lesions and vascular lesions were scored according to the established histopathological classification of Diabetic Nephropathy, as given by Tervaert. ${ }^{[7]}$

The glomerular lesions were classified as follows-

Class I- glomerular basement membrane thickening ( $>430 \mathrm{~nm}$ in males and $395 \mathrm{~nm}$ in females)

Class IIa- mild mesangial expansion

Class IIb- severe mesangial expansion.

Class III- nodular sclerosis and $<50 \%$ globallly sclerotic glomeruli.

Class IV- global glomerulosclerosis in $>50 \%$ of the glomeruli.
Interstitial inflammation and tubular atrophy (IFTA) were scored as follows: 0 , absent; $1,<25 \% ; 2,25-50 \% ; 3,>50 \%$ of the total area. Interstitial inflammation was scored as follows:0, absent; 1 , inflammation only in areas with IFTA; 2, inflammation in areas without IFTA. Arteriolar hyalinosis was scored as follows: 0 , absent; 1 , at least one area of arteriolar hyalinosis and 2, more than one area of arteriolar hyalinosis. Arteriosclerosis was scored as follows: 0 , no intimal thickening; 1 , intimal thickening less than thickness of media; 2, intimal thickening more than thickness of media. Initially, we found 97 adult patients with type $2 \mathrm{DM}$, however complete clinical and laboratory data was available in only 80 patients. Of these, 13 cases had almost normal looking glomeruli. In the absence of electron microscopy in our institute, these cases could not be further differentiated as Class 1 or normal glomeruli. Hence, 67 cases with recognizable light microscopic changes consistent with DN were finally included in the clinicopathologic analysis.

We further analysed the cases as: Albuminuric and Normoalbuminuric Diabetic Nephropathy

Diagnosis of Diabetic Nephropathy: The presence of clinical Diabetic Nephropathy was determined through the clinical records of the patient. DN was considered to be present when urine dipstick test was positive for proteinuria from trace to $3+$.

Absence of a clinical diagnosis of Diabetic Nephropathy: Absence of proteinuria as determined by urine dipstick test results; however histological lesions consistent with Diabetic Nephropathy was seen on light microscopy in patient with history of diabetes. These cases were further divided on the basis of eGFR.

eGFR at baseline was categorised as maintained $(>60 \mathrm{ml} /$ $\left.\mathrm{min} / 1.73 \mathrm{~m}^{2}\right)$ and low $\left(\leq 60 \mathrm{ml} / \mathrm{min} / 1.73 \mathrm{~m}^{2}\right)$.

\section{Statistical Analysis:}

For statistical analysis data was entered into a Microsoft excel spreadsheet and then analysed by SPSS (version 25.0; SPSS Inc., Chicago, IL, USA) and GraphPad Prism version5. Data was expressed as mean for numerical variables and percentages for categorical variables. Oneway analysis of variance (one-way ANOVA) was used to compare means of three or more 80samples for numerical data (using the $\mathrm{F}$ distribution). The histopathological data were analysed using the chi-squared test. Differences with a p-value $\leq 0.05$ was considered statistically significant.

\section{Results}

The baseline characteristics of 67 Type 2 adult diabetic patients is summarized in Table 1 . The mean age was 61.5 
years and $55.2 \%$ of the patients were females.55 of the 67 patients presented with proteinuria while 17.9\% (12/67) of the patients were normoalbuminuric and did not have any clinical manifestations of diabetic kidney disease, in spite of having histological lesions consistent with DN and hence, were not diagnosed clinically. Also, these patients were negative for urinary microalbumin. We also observed that 8 out of $12(66.6 \%)$ patients had reduced eGFR $\leq 60 \mathrm{ml} /$ $\mathrm{min} / 1.73 \mathrm{~m}^{2}$ with normoalbuminuria while $33.3 \%(4 / 12)$ had maintained eGFR. Table 2. demonstrates the clinical and pathological features of albuminuric and normoalbuminuric diabetic patients. There was no difference in the glomerular lesions[fig. 1,2,3] in the normoalbuminuric group when the eGFR was $\leq 60 \mathrm{ml} / \mathrm{min} / 1.73 \mathrm{~m}^{2}$ and when eGFR was $>60 \mathrm{ml} /$ $\min / 1.73 \mathrm{~m}^{2}$. Interstitial fibrosis and tubular atrophy[fig.4] were not seen in the normoalbuminuric DN group with eGFR $>60 \mathrm{ml} / \mathrm{min} / 1.73 \mathrm{~m}^{2}$, however $50 \%$ of the patients with $\mathrm{eGFR} \leq 60 \mathrm{ml} / \mathrm{min} / 1.73 \mathrm{~m}^{2}$ showed presence of IFTA. Also, significant amount of arteriosclerosis (50\%) was noted in the normoalbuminuric DN group with eGFR $\leq 60 \mathrm{ml} / \mathrm{min} / 1.73 \mathrm{~m}^{2}$

$10.2 \%$ of the patients in the albuminuric DN group with $\mathrm{eGFR} \leq 60 \mathrm{ml} / \mathrm{min} / 1.73 \mathrm{~m}^{2}$ showed presence of haematuria which was statistically significant. $(\mathrm{P}<0.0001)$ Also, this group had DN Class 4 lesions (6.1\%), arteriosclerosis Grade 2(18.3\%) lesions and IFTA Grade 2(28.5\%) and $3(6.1 \%)$ lesions which were not seen in the albuminuric DN Group with eGFR $>60 \mathrm{ml} / \mathrm{min} / 1.73 \mathrm{~m}^{2}$.

eGFR $\leq 60 \mathrm{ml} / \mathrm{min} / 1.73 \mathrm{~m}^{2}$ was associated with mortality due to renal causes.

Table 1: Baseline characteristics of the cohort.

\begin{tabular}{|l|l|}
\hline Baseline characteristics & Percentage or Mean \pm SD \\
\hline Male $(\mathrm{n}=30)$ & $44.8 \%$ \\
\hline Female $(\mathrm{n}=37)$ & $55.2 \%$ \\
\hline Age $($ years $)$ & $61.5 \pm 11.86$ \\
\hline Duration of diabetes $(\mathrm{yrs})$ & $12.8 \pm 9.9$ \\
\hline Serum Creatinine $(\mathrm{mg} / \mathrm{dl})$ & $2.53 \pm 2.66$ \\
\hline Hemoglobin $(\mathrm{gm} / \mathrm{dl})$ & $10.38 \pm 2.24$ \\
\hline Hypertensive patients $(\mathrm{n}=45)$ & $67.2 \%$ \\
\hline Non-hypertensive patients $(\mathrm{n}=22)$ & $32.8 \%$ \\
\hline Hypertensive patients on treatment $(\mathrm{n}=31)$ & $68.9 \%$ \\
\hline Hypertensive patients not on treatment $(\mathrm{n}=14)$ & $31.1 \%$ \\
\hline Diabetic patients on treatment $(\mathrm{n}=53)$ & $79.1 \%$ \\
\hline Diabetic patients not on treatment $(\mathrm{n}=14)$ & $20.9 \%$ \\
\hline Systolic Blood Pressure $(\mathrm{mmHg})$ & $129.1 \pm 29.58$ \\
\hline Diastolic Blood Pressure $(\mathrm{mmHg})$ & $80 \pm 13.58$ \\
\hline eGFR (ml/min/1.73m $\left.{ }^{2}\right)$ & $33.3 \pm 21.66$ \\
\hline
\end{tabular}

eGFR-estimated glomerular filtration rate, All hypertensive patients receiving treatment were on angiotensin receptor blockers/ACE inhibitors either singly or in combination with other blood pressure lowering drugs.

Table 2:Demographic and clinical features of albuminuric and normoalbuminuric Diabetic Nephropathy patients.

\begin{tabular}{|c|c|c|c|c|c|c|c|c|}
\hline & \multicolumn{3}{|c|}{ Albuminuric $\mathrm{DN}(\mathrm{n}=55)$} & \multicolumn{3}{|c|}{ Normoalbuminuric DN(n=12) } & \multirow{2}{*}{\begin{tabular}{|l|} 
Albuminuric \\
and Normo \\
albuminuric \\
DN (eGFR $\leq 60$ ) \\
P values
\end{tabular}} & \multirow{2}{*}{$\begin{array}{l}\text { Albuminuric and } \\
\text { Normoalbuminuric } \\
\text { DN (eGFR }>60 \text { ) } \\
\text { P values }\end{array}$} \\
\hline & eGFR $\leq 60$ & $(e G F R>60)$ & $P$ value & eGFR $\leq 60$ & eGFR $>60$ & $P$ value & & \\
\hline No of patients & 49 & 6 & & 8 & 4 & & & \\
\hline Age (years) & 62.5 & 54.16 & 0.698 & 65.62 & 52.25 & 0.687 & 0.125 & 0.212 \\
\hline $\begin{array}{l}\text { Sex } \\
\text { Male } \\
\text { Female }\end{array}$ & $\begin{array}{l}42.8 \% \\
57.2 \%\end{array}$ & $\begin{array}{l}66.7 \% \\
33.3 \%\end{array}$ & 0.554 & $\begin{array}{l}25 \% \\
75 \%\end{array}$ & $\begin{array}{l}50 \% \\
50 \%\end{array}$ & 0.568 & 0.658 & 0.235 \\
\hline
\end{tabular}




\begin{tabular}{|c|c|c|c|c|c|c|c|c|}
\hline & \multicolumn{3}{|c|}{ Albuminuric DN(n=55) } & \multicolumn{3}{|c|}{ Normoalbuminuric DN(n=12) } & \multirow{2}{*}{$\begin{array}{l}\text { Albuminuric } \\
\text { and Normo } \\
\text { albuminuric } \\
\text { DN (eGFR } \leq 60) \\
P \text { values }\end{array}$} & \multirow{2}{*}{$\begin{array}{l}\text { Albuminuric and } \\
\text { Normoalbuminuric } \\
\text { DN (eGFR }>60 \text { ) } \\
\text { P values }\end{array}$} \\
\hline & eGFR $\leq 60$ & $($ eGFR>60) & $P$ value & eGFR $\leq 60$ & eGFR>60 & P value & & \\
\hline Duration (yrs) & 13.8 & 6.38 & 0.985 & 13 & 10.5 & 0.654 & 0.102 & 0.658 \\
\hline SBP $(\mathrm{mmHg})$ & 135 & 130 & 0.235 & 124.28 & 130 & 0.265 & 0.354 & 0.09 \\
\hline DBP (mmHg) & 83.33 & 80 & 0.254 & 78.57 & 82.5 & 0.285 & 0.315 & 0.114 \\
\hline Hematuria & $5(10.2 \%)$ & 0 & $<0.0001$ & 0 & 0 & N/A & $<0.0001$ & N/A \\
\hline $\begin{array}{l}\text { Cause of death } \\
\text { Vascular event } \\
\text { Renal } \\
\text { Infection }\end{array}$ & \begin{tabular}{|l}
$16(32.6 \%)$ \\
$4(8.1 \%)$ \\
$8(16.3 \%)$
\end{tabular} & $\begin{array}{l}3(80.5 \%) \\
0 \\
2(33.3 \%)\end{array}$ & 0.268 & $\begin{array}{l}1(12.5 \%) \\
1(12.5 \%) \\
1(12.5 \%)\end{array}$ & $\begin{array}{l}2(50 \%) \\
0 \\
0\end{array}$ & 0.247 & 0.142 & 0.175 \\
\hline
\end{tabular}

eGFR-estimated glomerular filtration rate; SBP-systolic blood pressure; DBP-diastolic blood pressure; DN-diabetic nephropathy.

Table 3: Biochemical features of albuminuric and normoalbuminuric Diabetic Nephropathy patients.

\begin{tabular}{|c|c|c|c|c|c|c|c|c|}
\hline & \multicolumn{3}{|c|}{ Albuminuric DN(n=55) } & \multicolumn{3}{|c|}{ Normoalbuminuric DN(n=12) } & \multirow{2}{*}{$\begin{array}{l}\text { Albuminuric } \\
\text { and Normo } \\
\text { albuminuric } \\
\text { DN (eGFR } \leq 60 \text { ) } \\
P \text { values }\end{array}$} & \multirow{2}{*}{$\begin{array}{l}\text { Albuminuric and } \\
\text { Normoalbuminuric } \\
\text { DN (eGFR>60) } \\
\text { P values }\end{array}$} \\
\hline & eGFR $\leq 60$ & $(e G F R>60)$ & P value & eGFR $\leq 60$ & eGFR $>60$ & P value & & \\
\hline $\begin{array}{l}\text { eGFR }(\mathrm{ml} / \\
\left.\mathrm{min} / 1.73 \mathrm{~m}^{2}\right)\end{array}$ & 27.78 & 84.63 & $<0.0001$ & 22.03 & 73.98 & $<0.0001$ & 0.354 & 0.854 \\
\hline $\begin{array}{l}\text { S. Creatinine } \\
\text { (mg/dl) }\end{array}$ & 2.75 & 0.79 & $<0.0001$ & 2.85 & 1.025 & $<0.0001$ & 0.110 & 0.526 \\
\hline $\begin{array}{l}\text { Hemoglobin } \\
\text { (gm/dl) }\end{array}$ & 10.3 & 12.2 & 0.598 & 8.98 & 10.7 & 0.640 & 0.256 & 0.418 \\
\hline
\end{tabular}

eGFR- estimated glomerular filtration rate; DN- diabetic nephropathy

Table 4: Histopathological features of albuminuric and normoalbuminuric Diabetic Nephropathy patients.

\begin{tabular}{|c|c|c|c|c|c|c|c|c|}
\hline & \multicolumn{3}{|c|}{ Albuminuric DN(n=55) } & \multicolumn{3}{|c|}{ Normoalbuminuric DN(n=12) } & \multirow{2}{*}{$\begin{array}{l}\text { Albuminuric } \\
\text { and Normo } \\
\text { albuminuric DN } \\
\text { (eGFR } \leq 60 \text { ) } \\
\text { P values }\end{array}$} & \multirow{2}{*}{$\begin{array}{l}\text { Albuminuric and } \\
\text { Normoalbuminuric } \\
\text { DN (eGFR }>60 \text { ) } \\
\text { P values }\end{array}$} \\
\hline & eGFR $\leq 60$ & $($ eGFR>60) & $P$ value & eGFR $\leq 60$ & eGFR>60 & \begin{tabular}{|l}
$P$ \\
value
\end{tabular} & & \\
\hline $\begin{array}{l}\text { DN class } \\
2 \mathrm{a} \\
2 \mathrm{~b} \\
3 \\
4\end{array}$ & $\begin{array}{l}0 \\
11(22.4 \%) \\
35(71.4 \%) \\
3(6.1 \%)\end{array}$ & $\begin{array}{l}0 \\
1(16.6 \%) \\
5(83.3 \%) \\
0\end{array}$ & 0.265 & $\begin{array}{l}2(25 \%) \\
4(50 \%) \\
1(12.5 \%) \\
1(12.5 \%)\end{array}$ & $\begin{array}{l}1(25 \%) \\
1(25 \%) \\
2(50 \%) \\
0\end{array}$ & 0.254 & 0.265 & 0.156 \\
\hline $\begin{array}{l}\text { IFTA } \\
0 \\
1 \\
2 \\
3\end{array}$ & $\begin{array}{l}19(38.7 \%) \\
13(26.5 \%) \\
14(28.5 \%) \\
3(6.1 \%)\end{array}$ & $\begin{array}{l}2(33.3 \%) \\
4(66.6 \%) \\
0 \\
0\end{array}$ & 0.546 & $\begin{array}{l}4(50 \%) \\
1(12.5 \%) \\
1(12.5 \%) \\
2(25 \%)\end{array}$ & $\begin{array}{l}4(100 \%) \\
0 \\
0 \\
0\end{array}$ & 0.587 & 0.452 & 0.145 \\
\hline $\begin{array}{l}\text { Interstitial } \\
\text { inflammation } \\
0 \\
1 \\
2\end{array}$ & $\begin{array}{l}24(48.9 \%) \\
19(38.7 \%) \\
6(12.2 \%)\end{array}$ & $\begin{array}{l}2(33.3 \%) \\
4(66.6 \%) \\
0\end{array}$ & 0.685 & $\begin{array}{l}5(62.5 \%) \\
0 \\
3(37.5 \%)\end{array}$ & $\begin{array}{l}4(100 \%) \\
0 \\
0\end{array}$ & 0.658 & 0.125 & 0.148 \\
\hline
\end{tabular}




\begin{tabular}{|c|c|c|c|c|c|c|c|c|}
\hline & \multicolumn{3}{|c|}{ Albuminuric DN(n=55) } & \multicolumn{3}{|c|}{ Normoalbuminuric $\mathrm{DN}(\mathrm{n}=12)$} & \multirow{2}{*}{$\begin{array}{l}\text { Albuminuric } \\
\text { and Normo } \\
\text { albuminuric DN } \\
\text { (eGFR } \leq 60 \text { ) } \\
\text { P values }\end{array}$} & \multirow{2}{*}{$\begin{array}{l}\text { Albuminuric and } \\
\text { Normoalbuminuric } \\
\text { DN (eGFR }>60) \\
P \text { values }\end{array}$} \\
\hline & eGFR $\leq 60$ & $(e G F R>60)$ & P value & eGFR $\leq 60$ & eGFR $>60$ & $\begin{array}{l}P \\
\text { value }\end{array}$ & & \\
\hline $\begin{array}{l}\text { Arteriolar } \\
\text { hyalinosis } \\
0 \\
1 \\
2\end{array}$ & $\begin{array}{l}10(20.4 \%) \\
6(12.2 \%) \\
33(67.3 \%)\end{array}$ & $\begin{array}{l}0 \\
2(33.3 \%) \\
4(66.6 \%)\end{array}$ & 0.547 & $\begin{array}{l}2(25 \%) \\
2(25 \%) \\
4(50 \%)\end{array}$ & $\begin{array}{l}0 \\
0 \\
4(100 \%)\end{array}$ & 0.587 & 0.165 & 0.118 \\
\hline $\begin{array}{l}\text { Arteriosclerosis } \\
0 \\
1 \\
2\end{array}$ & $\begin{array}{l}13(26.5 \%) \\
27(55.1 \%) \\
9(18.3 \%)\end{array}$ & $\begin{array}{l}2(33.3 \%) \\
4(66.6 \%) \\
0\end{array}$ & 0.487 & $\begin{array}{l}4(50 \%) \\
3(37.5 \%) \\
1(12.5 \%)\end{array}$ & $\begin{array}{l}3(75 \%) \\
1(25 \%) \\
0\end{array}$ & 0.456 & 0.125 & 0.135 \\
\hline
\end{tabular}

eGFR- estimated glomerular filtration rate; DN- diabetic nephropathy; IFTA-interstitial fibrosis and tubular atrophy.

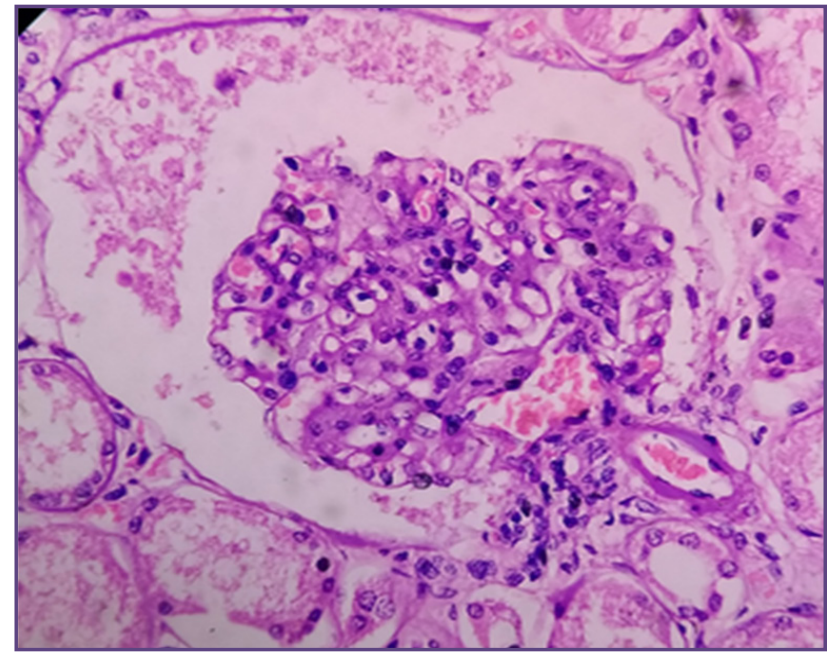

Fig. 1: Glomeruli showing mild mesangial matrix expansion with arteriolar hyalinosis. Diabetic Nephropathy Class 2a (400x H\&E).

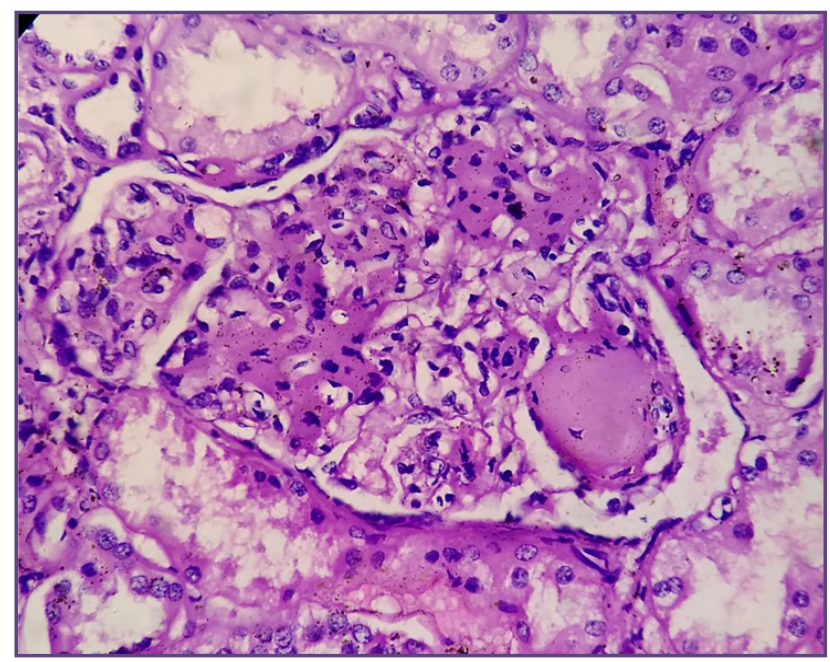

Fig 3: Glomerulus with single well developed Kimmelstiel Wilson nodule at 4'o clock. (400x H\&E).

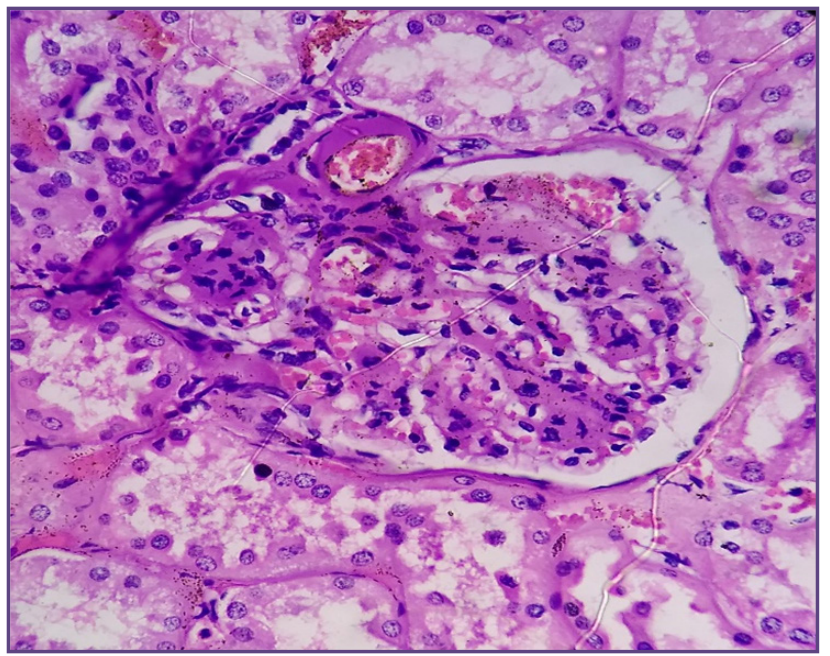

Fig. 2: Glomeruli showing severe mesangial matrix expansion with arteriolar hyalinosis. Diabetic Nephropathy Class 2 b (400x H\&E).

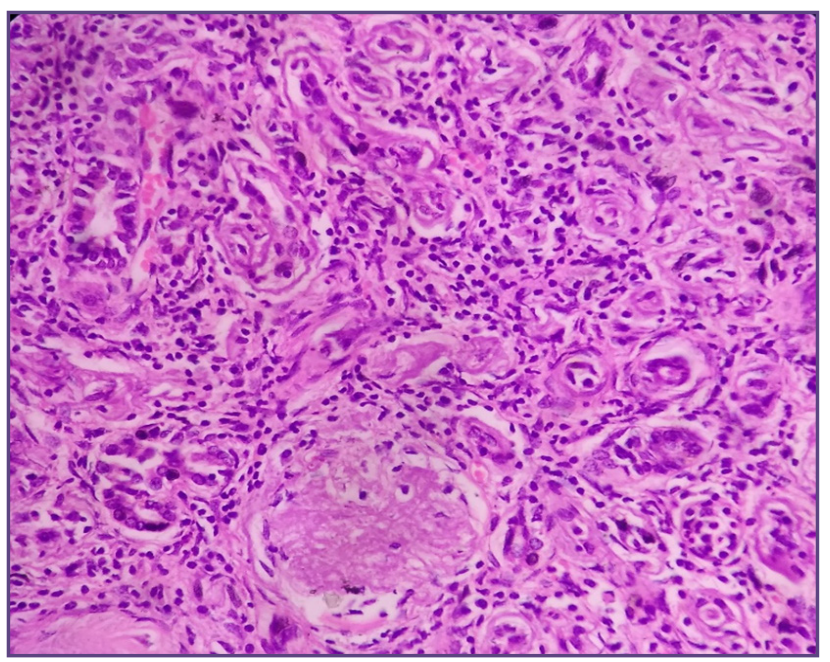

Fig 4: Interstitial fibrosis and tubular atrophy in a case of Diabetic Nephropathy. (400x, H\&E). 


\section{Discussion}

In our autopsy study of 67 diabetic patients, 55 patients had histological lesions attributable to DN with associated clinical manifestations, however $12(17.9 \%)$ patients had no proteinuria, including microalbuminuria in their lifetime but had histological lesions of Diabetic Nephropathy at autopsy. Our findings are in accordance with the study by Klessens et $\mathrm{al}^{[2]}$ and a recent study by Comai et al ${ }^{[8]}$. Klessens et al ${ }^{[2]}$ conducted an autopsy study on adult Diabetic Caucasian patients and observed that 20 of $106(18.8 \%)$ patients had histologically proven DN at autopsy, with no clinical manifestations of nephropathy during their lifetime. Comai et al ${ }^{[8]}$ studied 42 kidney biopsies from diabetic deceased kidney donors and reported that 32 of 35 donors had histological lesions of DN without any clinical or laboratory manifestations of renal dysfunction.

The old school thought of progression of DN from glomerular hyperfiltration, to microalbuminuria, to proteinuria ${ }^{[9]}$ has now undergone a revolution with studies which have shown that the presentation of Diabetic Kidney Disease is indeed more heterogenous. ${ }^{[10,11]}$ In the UKPDS study, after 15 years of follow up, $28 \%$ had developed an eGFR $<60 \mathrm{ml} / \mathrm{min}$ and $14 \%$ had no albuminuria. ${ }^{[12]}$ In a cross-sectional study, Kramer et al ${ }^{[13]}$ from US, reported the prevalence of normoalbuminuria in Type 2DM to be as high as 33\%. Penno et al reported that among 2959 DM patients with renal dysfunction, $56.6 \%$ were normoalbuminuric. ${ }^{[14]}$ Our study is the first to report the presence of histologically proven normoalbuminuric diabetic kidney disease at autopsy in the Indian population.

We also observed that 8 out of $12(66.6 \%)$ patients had reduced eGFR $\leq 60 \mathrm{ml} / \mathrm{min} / 1.73 \mathrm{~m}^{2}$ with normoalbuminuria. Our findings are in line with various recent studies which have reported that a sizable proportion of diabetic patients with reduced eGFR have no albuminuria. ${ }^{[15,16,17]}$ Shimizu et al ${ }^{[16]}$ have reported a $34.8 \%$ prevalence of reduced eGFR in normoalbuminuric biopsy proven diabetic nephropathy patients. In the DEMAND (Developing Education on Microalbuminuria for Awareness of Renal and Cardiovascular Risk in Diabetes) Study, 52.4\% of the patients presented with normoalbuminuria and $17 \%$ of them had reduced eGFR $\left(\leq 60 \mathrm{ml} / \mathrm{min} / 1.73 \mathrm{~m}^{2}\right)^{[17]}$

$33.3 \%$ of the normoalbuminuric diabetic patients had maintained eGFR $\left(>60 \mathrm{ml} / \mathrm{min} / 1.73 \mathrm{~m}^{2}\right)$ with histologic lesions of DN. It is this proportion of Diabetic patients which remain clinically underdiagnosed as they do not have significant proteinuria and eGFR $<60 \mathrm{ml} / \mathrm{min} / 1.73 \mathrm{~m}^{2}$. Routine Kidney biopsies will help in the timely diagnosis of these normoalbuminuric subjects who are in the early stages of Chronic Kidney Disease. There are very few studies which have previously described the presence of histologically proven NADKD in the absence of CKD. Comai et $\mathrm{al}^{[8]}$ have reported the prevalence of NADKD with $\mathrm{eGFR}>60 \mathrm{ml} / \mathrm{min} / 1.73 \mathrm{~m}^{2}$ as high as $91.4 \%$. This may be a result of selection bias as these subjects were candidates for donors for cadaveric kidney transplantation. They studied kidney biopsies which contained around 30 glomeruli per section. In our autopsy study, we had the advantage of studying more 100 glomeruli which enabled us to not only confirm the presence of DKD but also evaluate the histological manifestations in various stages of renal dysfunction and appropriately classify them. This being an autopsy study, selection bias was eliminated.

In our study, the most represented DN class in NADKD was $2 \mathrm{~b}$ which means severe mesangial expansion. Also, the percentage of glomeruli with nodular sclerosis in Type 3 DN class was $11 \%$, which was similar to the findings by Klessens et al ${ }^{[2]}$ and Comai et al ${ }^{[8]}$. We also observed that normoalbuminuric patients with reduced eGFR $\left(\leq 60 \mathrm{ml} / \mathrm{min} / 1.73 \mathrm{~m}^{2}\right)$ showed significant amount of interstitial fibrosis and tubular atrophy $(50 \%)$ as compared to those with eGFR $>60 \mathrm{ml} / \mathrm{min} / 1.73 \mathrm{~m}^{2}$, however there was no difference in the glomerular lesions between the two groups. There was not much difference in the IFTA scores in patients with low $\left(e G F R \leq 60 \mathrm{ml} / \mathrm{min} / 1.73 \mathrm{~m}^{2}\right)$ irrespective of the proteinuria. Among patients with reduced $\mathrm{eGFR} \leq 60 \mathrm{ml} / \mathrm{min} / 1.73 \mathrm{~m}^{2}$, glomerular lesions 3,4 were significantly more in patients with albuminuria $(77.5 \%)$ as compared to those with normoalbuminuria $(25 \%)$ These findings indicate that albuminuria correlates with the glomerular lesions. Also, even in the absence of proteinuria, some amount of interstitial fibrosis and tubular atrophy is seen, suggesting that the kidneys in some diabetic patients have already undergone glomerular and tubulointerstitial damage. A recent study has implicated arteriolopathy as the mechanism for this non proteinuric type of DN. ${ }^{[18]}$ However, further studies are needed to determine the pathogenesis of NADKD. Said and Nasr [19], have suggested that in the early stages of DKD, the renal tubules are healthy and retain the capacity to reabsorb proteins in spite of leakage because of glomerular damage. This may explain the histological lesions of DN in the absence of proteinuria. Tubulointerstitial damage appears to be a key factor in the pathogenesis of DKD and a significant amount of such patients who do not show any clinical manifestations can progress to chronic renal failure.

The limitation in our study is the nonavailability of Transmission electron microscopy, hence we could not evaluate Class 1 DN lesions. We have included only cases with identifiable light microscopic changes. As this 
is an autopsy study with 3 years retrospective analysis, immunofluorescence could not be performed. Furthermore, proteinuria was detected by dipstick method, which means microalbuminuria may not have been detected. Nodular lesions may also be seen in elderly non diabetic patients with hypertension; however, it seems unlikely that our results are affected by this as only one out of the three patients with Type 3 lesions had hypertension, and was on antihypertensive for the same.

Kidney biopsies are not routinely performed in diabetic patients with normoalbuminuria, and the decision to perform renal biopsies is solely at the discretion of the clinician. Major indications for performing kidney biopsy in Diabetic patients include massive proteinuria with no proven diabetic retinopathy, presence of haematuria and unexplained rapid deterioration of renal function. ${ }^{[2,21]} \mathrm{A}$ recent study has revealed that the clinical characteristics of $\mathrm{DKD}$, i.e. duration of diabetes, level of proteinuria, and eGFR $<60 / \mathrm{ml} / \mathrm{min} / 1.73 \mathrm{~m}^{2}$ do not accurately indicate the renal dysfunction. ${ }^{[22]}$ This finding however requires further validation. In the current study, we have shown the histological presence of almost all classes of DN, in the absence of proteinuria.

Several studies in recent times have reported the discovery and validation of non-invasive biomarkers for predicting disease progression and response to treatment in DKD. ${ }^{[23,24]}$ However, these studies need further validation for implementation in clinical practice. With various novel pharmacological agents such as baricitinib, a selectively Janus kinase 1 inhibitor; ruboxistaurin, a protein kinase $\mathrm{c} \beta$ inhibitor; pentoxyphylline, an anti-inflammatory and antifibrotic agent; currently under trial, ${ }^{[25]}$ a miracle drug for Diabetic Kidney Disease is not far away. In the near future with the advent of new pharmacologic agents, a kidney biopsy to evaluate the progression of disease in the absence of clinical manifestations will be helpful. Recently, FDA has approved a new drug Canagliflozin for the treatment of Diabetes related Kidney Disease. Thus, for now we can say that, kidney biopsy is important to determine the various patterns of DN and also to diagnose early stages of DKD with maintained eGFR.

\section{Conclusion}

From this autopsy study, we can therefore conclude that there is a subset of DKD, NADKD which cannot be diagnosed clinically. Histopathological changes consistent with DN may be seen even in the absence of clinical manifestations. The diagnosis of early stages of NADKD maybe missed in the absence of kidney biopsy. Further studies need to be done to evaluate the role of kidney biopsy in Diabetes Mellitus.

\section{Acknowledgements}

None

\section{Funding}

Nil

\section{Competing Interests}

Nil

\section{References}

1. Unnikrishnan RI, Rema M, Pradeepa R, Deepa M, Shanthirani CS, Deepa R, Mohan V. Prevalence and risk factor of diabetic nephropathy in an urban south Indian population; The Chennai urban rural Epidemiology study (CURES-45) Diabetes Care. 2007;30:2019-2024.

2. Klessens CQ, Woutman TD, Veraar KA, Zandbergen M, Valk EJ, Rotmans JI, Wolterbeek R, Bruijn JA, Bajema IM. An autopsy study suggests that diabetic nephropathy is underdiagnosed. Kidney Int.2016;90:149-156.

3. Tsalamandris C, Allen TJ, Gilbert RE, Sinha A, Panagiotopoulos S, Cooper ME, Jerums G. Progressive decline in renal function in diabetic patients with and without albuminuria. Diabetes.1994;43:649-655.

4. Chen C, Wang C, Hu C, Han Y, Zhao L, Zhu X, Xiao L, Sun L. Normoalbuminuric diabetic kidney disease. Front Med. 2017;11:310-318.

5. MC,MacisaacRJ,JerumsG, WeekesA,MoranJ,ShawJE, Atkins RC. Nonalbuminuric renal impairment in type 2 diabetic patients and in the general population (national evaluation of the frequency of renal impairment cO-existing with NIDDM [NEFRON] 11). Diabetes Care.2009;32:14971502.

6. American Diabetes Association. Standards of medical care in diabetes - 2015 abridged for primary care providers. Clin Diabetes.2015;33:97-111.

7. Tervaert TWC, Mooyaart AL, Amann K, Cohen AH, Cook HT, Drachenberg CB Ferrario F, Fogo AB, Haas M, de Heer E, Joh K, Noël LH, Radhakrishnan J, Seshan SV, Bajema IM, Bruijn JA; Renal Pathology Society. Pathologic Classification of Diabetic Nephropathy. J. Am. Soc. Nephrol. 2010;21:556-563

8. Comai G, Malvi D, Angeletti A, Vasuri F, Valente S, Ambrosi F, Capelli I, Ravaioli M, Pasquinelli G, D'Errico A, Fornoni A, La Manna G. Histological Evidence of Diabetic Kidney Disease Precede Clinical Diagnosis. Am J Nephrol. 2019;50:29-36.

9. Adler AI, Stevens RJ, Manley SE, Bilous RW, Cull CA, Holman RR; UKPDS GROUP. Development and progression of nephropathy in type 2 diabetes: The United Kingdom Prospective Diabetes Study (UKPDS 64). Kidney Int. 2003; 63:225-232.

10. Gesualdo L, Di Paolo S. Renal lesions in patients with type 2 diabetes: a puzzle waiting to be solved. Nephrol Dial Transplant. 2015;30:155-157. 
11. Fiorentino M, Bolignano D, Tesar V, Pisano A, Biesen WV, TripepiG,D’Arrigo G, Gesualdo L; ERA-EDTA Immunonephrology Working Group. Renal biopsy in patients with diabetes: a pooled meta-analysis of 48 studies. Nephrol Dial Transplant. 2017; 32: 97-110.

12. Retnakaran R, Cull CA, Thorne KI, Adler AI, Holman RR. UKPDS Study Group. Risk factors for renal dysfunction in type 2 diabetes: U.K. Prospective Diabetes Study 74. Diabetes. 2006;55:1832-1839.

13. Kramer HJ, Nguyen QD, Curhan G, Hsu CY. Renal insufficiency in the absence of albuminuria and retinopathy among adults with type 2 diabetes mellitus. JAMA. 2003;289:3273-7.

14. Penno G, Solini A, Bonora E, Fondelli C, Orsi E, Zerbini G, Trevisan R, Vedovato M, Gruden G, Cavalot F, Cignarelli M, Laviola L, Morano S, Nicolucci A, Pugliese G; Renal InsufficiencyAnd Cardiovascular Events (RIACE) Study Group. Clinical significance of nonalbuminuric renal impairment in type 2 diabetes. J Hypertens. 2011;29:18021809.

15. MacIsaac RJ, Tsalamandris C, Panagiotopoulos S, Smith TJ, McNeil KJ, Jerums G. Nonalbuminuric renal insufficiency in type 2 diabetes. Diabetes Care. 2004;27:195-200.

16. Shimizu M, Furuichi K, Toyama T, Kitajima S, Hara A, Kitagawa K, Iwata Y, Sakai N, Takamura T, Yoshimura M, Yokoyama H, Kaneko S, Wada T; Kanazawa Study Group for Renal Diseases and Hypertension. Long-term outcomes of Japanese type 2 diabetic patients with biopsyproven diabetic nephropathy.Diabetes Care. 2013;36:36553662 .
17. Dwyer JP, Parving HH, Hunsicker LG, Ravid M, Remuzzi G, Lewis JB. Renal Dysfunction in the Presence of Normoalbuminuria in Type 2 Diabetes: results from the DEMAND Study. Cardiorenal Med. 2012;2:1-10.

18. Uzu T, Kida Y, Shirahashi N, Harada T, Yamauchi A, Nomura M,Isshiki K, Araki S, Sugimoto T, Koya D, Haneda M, Kashiwagi A, Kikkawa R. Cerebral microvascular disease predicts renal failure in type 2 diabetes. J Am Soc Nephrol. 2010;21:520-526.

19. Said SM, Nasr SH. Silent diabetic nephropathy.Kidney Int. 2016;90:24-6.

20. Sharma SG, Bomback AS, Radhakrishnan J, Herlitz LC, Stokes MB, Markowitz GS,D'Agati VD. The modern spectrum of renal biopsy findings in patients with diabetes. Clin J Am Soc Nephrol. 2013;8:1718-1724.

21. Ghani AA, Waheeb SA, Sahow AA, Hussain N. Renal biopsy in patients with type 2 diabetes mellitus: indications and nature of the lesions. Ann Saudi Med. 2009;29:450-453.

22. Zhuo L, Zhang N, Zou G, Chen D, Li W. Clinical characteristics and outcomes of biopsyproven diabetic nephropathy. Front Med. 2017;11:386-392.

23. Mulder S, Hamidi H, Kretzler M, Ju W. An integrative systems biology approach for precision medicine in diabetic kidney disease. Diabetes ObesMetab. 2018;20:6-13.

24. Looker HC, Mauer M, Nelson RG. Role of Kidney Biopsies for Biomarker Discovery in Diabetic Kidney Disease. Adv Chronic Kidney Dis. 2018;25:192-201.

25. Alicic RZ, Rooney MT, Tuttle KR. Diabetic kidney disease challenges, progress, and possibilities. Clin J Am Soc Nephrol. 2017;12:2032 $\square 2045$.

*Corresponding author:

Dr. Sonal Paul, A-5/102, Chabhaiya Park, Kapurwadi, Thane (w)-400607

Phone: +91 9930856879

Email: sonalpaul1993@gmail.com

Date of Submission : 11/05/2020

Date of Acceptance : 17/08/2020

Financial or other Competing Interests: None.
Date of Publication : 30/10/2020 